Research paper

\title{
Purifying selection and concerted evolution of RNA-sensing toll-like receptors in migratory waders
}

\author{
Nynke Raven ${ }^{a}$, Simeon Lisovski ${ }^{a}$, Marcel Klaassen ${ }^{a}$, Nathan Lo ${ }^{\text {b }}$, Thomas Madsen ${ }^{\text {a }}$, \\ Simon Y.W. Ho ${ }^{\text {b }}$, Beata Ujvari ${ }^{\mathrm{a}, *}$ \\ a Centre for Integrative Ecology, School of Life and Environmental Sciences, Deakin University, Waurn Ponds, VIC 3216, Australia \\ b School of Life and Environmental Sciences, The University of Sydney, Sydney, NSW 2006, Australia
}

\section{A R T I C L E I N F O}

Article history:

Received 10 December 2016

Received in revised form 15 May 2017

Accepted 17 May 2017

Available online 18 May 2017

\section{Keywords:}

Migratory birds

Toll-like receptor

Concerted evolution

Avian influenza virus

Purifying selection

Episodic selection

\begin{abstract}
A B S T R A C T
Migratory birds encounter a broad range of pathogens during their journeys, making them ideal models for studying immune gene evolution. Despite the potential value of these species to immunoecology and disease epidemiology, previous studies have typically focused on their adaptive immune gene repertoires. In this study, we examined the evolution of innate immune genes in three long-distance migratory waders (order Charadriiformes). We analysed two parts of the extracellular domains of two Toll-like receptors (TLR3 and TLR7) involved in virus recognition in the Sanderling (Calidris alba), Red-necked Stint (Calidris ruficollis), and Ruddy Turnstone (Arenaria interpres). Our analysis was extended to 50 avian species for which whole-genome sequences were available, including two additional waders. We found that the inferred relationships among avian TLR3 and TLR7 do not match the whole-genome phylogeny of birds. Further analyses showed that although both loci are predominantly under purifying selection, the evolution of the extracellular domain of avian TLR3 has also been driven by episodic diversifying selection. TLR7 was found to be duplicated in all five wader species and in two other orders of birds, Cuculiformes and Passeriformes. The duplication is likely to have occurred in the ancestor of each order, and the duplicated copies appear to be undergoing concerted evolution. The phylogenetic relationships of wader TLR7 matched those of the five wader species, but that of TLR3 did not. Instead, the tree inferred from TLR3 showed potential associations with the species' ecology, including migratory behaviour and exposure to pathogens. Our study demonstrates the importance of combining immunological and ecological knowledge to understand the impact of immune gene polymorphism on the evolutionary ecology of infectious diseases.
\end{abstract}

(c) 2017 Elsevier B.V. All rights reserved.

\section{Introduction}

The regular, directed movements of large numbers of migratory animals have been shown to facilitate the long-distance dispersal of zoonotic pathogens (Altizer et al., 2011; Fritzsche McKay and Hoye, 2016). Recent examples include the spread of Ebola virus by migratory fruit bats (Leroy et al., 2009), West Nile virus by migratory songbirds (Owen et al., 2006), and avian influenza viruses (AIV) by migratory waterbirds (Krauss et al., 2010; Marius et al., 2006; Verhagen et al., 2015). Long-distance migration also leads to increased metabolic activity (Altizer et al., 2011; Klaassen et al., 2012), and a concomitant reduction in immune function (Møller et al., 2004; Møller and Erritzøe, 1998; Råberg et al., 1998).

Each breeding area, stopover site, and wintering ground has its own unique pathogen community (Altizer et al., 2011), so that migratory birds encounter a greater diversity of pathogens than do non-migratory

\footnotetext{
* Corresponding author.

E-mail address: beata.ujvari@deakin.edu.au (B. Ujvari).
}

birds (Figuerola and Green, 2000). In combination with high bird density at stopover sites (Krauss et al., 2010), these factors increase the risk of pathogen exposure, and consequently the overall infection risk (Koprivnikar and Leung, 2015). Pathogens have been shown to impair migratory ability (Bradley and Altizer, 2005; van Gils et al., 2007), which ultimately results in reduced reproductive success (Asghar et al., 2011). The physiological and pathological impacts associated with the migratory lifestyle act as strong evolutionary drivers of avian immune systems (Minias et al., 2016; Møller and Erritzøe, 1998). Therefore, immune gene variation is likely to have important implications for understanding the disease ecology of migratory birds.

The innate immune system initiates host immune and inflammatory responses designed to eliminate a diverse community of pathogens (Aderem and Ulevitch, 2000; Hellgren, 2015; Takeda et al., 2003; Tschirren et al., 2013), and hence provides the first line of immunological defence in vertebrates (Medzhitov and Janeway, 1997). Innate immune genes such as the Toll-like receptors are highly conserved across species (Beutler and Rehli, 2002), but still exhibit high species-specific genetic variation (Cormican et al., 2009). Therefore, these genes are ideal 
candidates for studying the evolution of host-parasite interactions in wild populations.

Toll-like receptors consist of transmembrane proteins that recognize essential and slow-evolving areas of the pathogen's genome called pathogen-associated molecular patterns (PAMPs) (Medzhitov and Janeway, 2000). PAMPs are recognized by receptors located within the TLR extracellular domain (ECD) (Medzhitov and Janeway, 1997), which consists of 19-25 leucine-rich repeats (LRRs) (Bell et al., 2003). Owing to external selection pressure, the ECD is the most variable region of a TLR (Botos et al., 2011). It is capped by N-terminal and C-terminal domains, with a transmembrane helix joining the ECD to the intracellular Toll-interleukin-1 receptor (TIR) domain. When activated, the TIR domain initiates a signalling cascade (De Nardo, 2015; Gay and Gangloff, 2007) that activates immune and inflammatory responses (Akira and Takeda, 2004). Variation within TLRs has been linked to disease susceptibility and resistance across vertebrates (Schröder and Schumann, 2005), but the most comprehensive studies have been conducted in humans (Misch and Hawn, 2008). Both overall genetic variability and single amino acid polymorphisms of TLRs have been shown to affect disease outcomes (Netea et al., 2012).

Ten different TLRs have been recorded in birds, each with an ability to recognize different PAMPs (Werling et al., 2009). TLR3 and TLR7, the only two endosomal TLRs in birds, recognize double-stranded RNA (Alexopoulou et al., 2001) and single-stranded RNA, respectively (Alcaide and Edwards, 2011; Diebold et al., 2004) (Table 1). TLR3 can also recognize single-stranded RNA via the complementary viral strand formed during the transcription and replication of RNA viruses in infected host cells (Resa-Infante et al., 2011). Therefore, TLR3 could potentially play an important role in recognizing influenza virus, including AIV infections. The evolution of TLRs has been studied in bats (EscaleraZamudio et al., 2015), humans (Roach et al., 2005), and various birds (Alcaide and Edwards, 2011; Brownlie and Allan, 2011; Cormican et al., 2009; Gonzalez-Quevedo et al., 2015; Grueber et al., 2015; Vinkler et al., 2014), including long-distant migrants such as the Tawny Pipit (Anthus campestris) (Gonzalez-Quevedo et al., 2015) and Lesser Kestrel (Falco naumanni) (Alcaide and Edwards, 2011). There have been a few studies focusing on adaptive immune genes, such as the major histocompability complex (MHC) in the long-distance migratory waders Red Knot (Calidris canutus) (Buehler et al., 2013) and Great Snipe (Gallinago media) (Ekblom et al., 2010; Ekblom et al., 2007). However, there have not been any attempts to decipher the evolution of innate immune genes, such as TLRs, in long-distance migratory shorebirds.

In addition to their important role in disease ecology and epidemiology, migratory shorebirds are also taxa of great conservation concern. During the last decade, environmental and anthropogenic factors have led to dramatic population declines (primarily due to habitat destruction) in migrants, with waders being a particularly noticeable example (Altizer et al., 2011; Wilcove and Wikelski, 2008). These declines have also been linked to increased exposure and susceptibility to disease (Klaassen et al., 2012), underscoring an urgent need for studies of relevant factors such as immune gene diversity and function.

The Ruddy Turnstone (Arenaria interpres), Red-necked Stint (Calidris ruficollis), and Sanderling (Calidris alba) are long-distance migratory waders in the sandpiper family (Scolopacidae). These three species winter on different coastline areas in Australia, but follow similar migratory paths through eastern Asia to breeding grounds in northern Russia and the Arctic Circle, making stopovers at the same or similar sites (Lisovski et al., 2015; Minton et al., 2010; Minton et al., 2011). Recent studies in south-east Australia found a high prevalence (25-30\%) of antibodies against AIV in the Ruddy Turnstone and Red-necked Stint, suggesting that these species frequently encounter the virus (Curran et al., 2014; Ferenczi, 2016). However, the Sanderling had no or a low level of AIV antibodies detected (Curran et al., 2014; Ferenczi, 2016). Recent research on AIV infections in migratory birds, notably regarding interspecific variation in susceptibility and dispersal potential, has focused on variation in ecological parameters or acquired immunity (Maxted et al., 2016). In contrast, the potential role of innate immune gene variation has largely been overlooked.

In this study we aimed to compare the levels of polymorphism in TLR3 and TLR7 across bird species. As TLRs have a diverse evolutionary history (Alcaide and Edwards, 2011), we commenced our study by cloning and sequencing loci encoding two distinct parts of the extracellular domain of TLR3 and TLR7 in A. interpres, C. ruficollis, and C. alba. We then investigated the diversity of these genes in the three waders. By including sequences from an additional 50 published avian genomes (Jarvis et al., 2015; Romanov et al., 2011; Zhang et al., 2014) we provide a comprehensive analysis of the selective forces involved in the evolution of avian TLR3 and TLR7.

\section{Materials and methods}

\subsection{Sampling and sequencing}

We studied three migratory wader species from the sandpiper family (Scolopacidae): Ruddy Turnstone (Arenaria interpres), Sanderling (Calidris alba), and Red-necked Stint (Calidris ruficollis). All live birds were captured on beaches located within a $30 \mathrm{~km}$ radius, during a 3day period in April 2013, from their wintering grounds on the coast of south-east Australia (breeding origin not known). Birds were caught using cannon nets by the Victorian Waders Study Group. Using a

Table 1

Comparison of the two RNA-recognizing Toll-like receptors (TLRs) in avian taxa.

\begin{tabular}{|c|c|c|}
\hline & $\begin{array}{l}\text { TLR3 } \\
\text { Across avian taxa }\end{array}$ & TLR7 \\
\hline Location of TLR & Endosomal membrane $^{a}$ & Endosomal membrane, ${ }^{\mathrm{b}}$ \\
\hline Length of gene & $2600 \mathrm{bp}^{\mathrm{a}}$ & $3200 \mathrm{bp}^{\mathrm{b}}$ \\
\hline Structure of the gene & Conserved across species ${ }^{c}$ & Conserved across species ${ }^{c}$ \\
\hline Duplicates discovered & No & Passerine birds ${ }^{\mathrm{d}}$ \\
\hline PAMPs recognized & dsRNA, approximately $40-50$ bp long ${ }^{\mathrm{e}}$ & ssRNA, small interfering RNAs, self-RNA ${ }^{\mathrm{b}}$ \\
\hline Diseases in birds associated with TLRs & $\begin{array}{l}\text { Duck reovirus }{ }^{\mathrm{f}} \text {, avian influenza virus }{ }^{\mathrm{g}} \text {, pigeon paramyxovirus } \\
\text { type } 1^{\text {h}} \text {, West Nile virus }{ }^{\mathrm{i}} \text { Marek's disease virus }{ }^{\mathrm{j}}\end{array}$ & Pigeon paramyxovirus type $1^{\mathrm{h}}$, avian influenza virus ${ }^{\mathrm{k}}$ \\
\hline
\end{tabular}

\footnotetext{
a Bell et al. (2005)

b Tanji et al. (2013).

c Alcaide and Edwards (2011).

d Cormican et al. (2009).

e Liu et al. (2008).

f Zhang et al. (2015).

g Downing et al. (2010); Koprivnikar and Leung (2015)

h Li et al. (2015).

i Wang et al. (2004)

j Hu et al. (2015).

k MacDonald et al. (2007).
} 
capillary tube, a blood sample was taken (approx. $50 \mu \mathrm{L}$ ) from the brachial vein from each bird. All bird catching and sampling was in accordance with animal ethics and state research permits. Blood samples were stored at $4{ }^{\circ} \mathrm{C}$ for $24 \mathrm{~h}$ before being centrifuged to separate plasma and red blood cells. All samples were stored at $-80^{\circ} \mathrm{C}$. We obtained a total of 18 samples of $A$. interpres, 22 samples of $C$. alba, and 17 samples of $C$. ruficollis. Two specimens per species were used in the detailed analyses of TLR gene evolution, while the remaining specimens were used in the population-level comparisons.

Sequenced bird genomes were retrieved from the study by Zhang et al. (2014), along with those sequenced subsequently from the Whitethroated Sparrow (Zonotrichia albicollis; Romanov et al., 2011) and Ruff (Calidris pugnax; genome sequencing and assembly project number PRJNA281024, released November 2015). A total of 50 bird genomes were analysed in the current study. Sequences of TLR3 and TLR7 from A. interpres that were generated during the course of this study were BLASTed against these 50 bird genomes. Scaffolds containing matches to the TLR3/TLR7 sequences from $A$. interpres were retrieved from GenBank and checked for completeness (i.e., containing complete open reading frames) and for the potential presence of multiple copies of the same gene. Only complete sequences were used in the study (Supplementary material S1, Tables S1 and S2).

DNA was extracted from $20 \mu \mathrm{L}$ of red blood cells using the phenol/ chloroform technique (Maniatis et al., 1982). The quantity and quality of the extracted DNA was established using a NanoDrop 2000 (ThermoFisher Scientific, Waltham, MA, USA), and the samples were diluted to $50 \mathrm{ng} / \mu \mathrm{L}$ for further analyses. The primers were designed to amplify regions of the ECD, TLR3 primers amplified 800 bp in the central region of the ECD, the primers for TLR7 amplified a 1000 bp region at the $3^{\prime}$ end of the ECD and a fraction of $5^{\prime}$ TIR. A detailed description of primer design, polymerase chain reactions, cloning, and sequencing can be found in the Supplementary material S1 (Table S3). All sequences generated in this study have been deposited in NCBI GenBank, with accession numbers KX823453-KX823575.

\subsection{Characterization of wader TLR3 and TLR7 genes}

Clones generated from the two specimens per wader species were included in the analyses described below. Sequences were aligned and checked in BioEdit 7.0 (Hall, 1999). Clone sequences sharing 100\% identity were discarded. The molecular structures of wader TLR3 and TLR7 were determined by aligning the clone sequences generated in this study with sequences from modern human (GenBank NP_003256, TLR3; NP_057646, TLR7), house mouse (GenBank NP_569054, TLR3; NP_573474 XP_918297, TLR7), and Killdeer (GenBank XP_009882203, TLR3; XP_009893509, TLR7). LRR regions were determined using a combination of Simple Modular Architecture Research Tool (SMART; Schultz et al., 1998) and previous LRR structural descriptions (Liu et al., 2008; Philbin et al., 2005; Tanji et al., 2013).

Three-dimensional protein structures were constructed using SWISSMODEL (Biasini et al., 2014). Templates for the ECD crystal structures of TLR3 (3CIG; Liu et al., 2008) and TLR8 (3W3K; Tanji et al., 2013) were retrieved from the Protein Data Bank (Berman et al., 2000) and were used with the cloned sequences. The entire TLR7 sequences generated by us were included in all the analyses except the 3D modelling. Since the template available in the Protein Databank (PDB) only contained a truncated TLR molecule, only regions of our TLR7 sequences that corresponded to the PDB template were visualized in 3D models. LRR regions were identified following the descriptions by Liu et al. (2008) and Tanji et al. (2013) and by using SMART. Swiss Pdb-Viewer 4.1.0 (Guex et al., 2009) was used to view the TLR molecular structures in 3D.

Genetic diversity indices of TLR3 and TLR7 within and between wader species were calculated using MEGA 6.0 (Tamura et al., 2013). Within- and between-group genetic distances were calculated using the Tajima-Nei substitution model (Tajima and Nei, 1984), with 500 bootstraps and with a value of 1 for the alpha parameter of the gamma distribution. Amino acid (AA) changes were identified between the cloned sequences. AA side-chain charges, polarity, and hydropathy indices were retrieved from the study by Weast and Lide (1991). Physicochemical distances among AA states at variable sites were quantified using Grantham's distance matrix (Grantham, 1974). Protein electrostatic and hydrophobic potentials were calculated using cloned sequences in PDB2PQR (Dolinsky et al., 2007; Dolinsky et al., 2004) using the PARSE force-field and electrostatic calculation performed in the APBS web solver (Baker et al., 2001). Surface charge distribution was visualized using PyMOL educational v 1.7.4 (DeLano, 2002).

\subsection{Phylogenetic analysis of TLR3 and TLR7 genes across birds}

In our phylogenetic analyses, we included TLR3 and TLR7 sequences identified from the 50 published bird genomes as well as representative sequences from the three wader species generated in this study. Since TLR3 has not been found to be duplicated in any of the 50 bird genomes, only one TLR3 sequence per wader specimen was included in the analyses. Owing to two copies of TLR7 being identified in some of the 50 bird genomes and in the waders studied here, the two TLR7 clone sequences with the largest number of identical clones per wader specimen were used in the TLR7 analyses.

Phylogenetic analyses of sequences from TLR3 and TLR7 were performed using maximum likelihood in RAxML 8 (Stamatakis, 2014). The GTR + G substitution model was identified as the best-fitting model of nucleotide substitution using the Bayesian information criterion. For each data set, the phylogeny was inferred using 10 random starts, and node support was evaluated using 1000 bootstrap replicates.

The phylogeny and node times were jointly estimated using Bayesian analysis in BEAST 1.8 (Drummond et al., 2012). For each data set, the analysis was performed using the GTR $+\mathrm{G}$ substitution model and with a Yule prior for the tree. To account for rate variation across branches, we used an uncorrelated lognormal relaxed clock (Drummond et al., 2006). To calibrate the estimate of the evolutionary timescale, we used the fossil-based age constraints described by Jarvis et al. (2014). For the TLR3 and TLR7 trees, we constrained the ages of eight and six nodes, respectively (Supplementary material S1, Table S4). Calibrations were only applied to nodes with posterior probabilities $>0.90$, and were implemented as uniform priors on node times.

The posterior distributions of parameters, including the tree and node times, were estimated by MCMC sampling. Samples were drawn every 2000 steps from a total of 20,000,000 steps, with the first $10 \%$ of samples discarded as burn-in. From the posterior sample of trees, we identified the maximum-clade-credibility tree and rescaled the node heights to match the median posterior estimates.

\subsection{Signatures of selection in TLR3 and TLR7 across birds}

As with the phylogenetic reconstruction, evolutionary analyses were conducted on TLR3 and TLR7 sequences identified from the 50 bird genomes and the three additional wader species. These included two specimens per species, one sequence of the TLR3 gene per wader specimen, and two sequences of the TLR7 gene per wader specimen.

Phylogenetic relationships among the sequences were estimated using neighbour-joining in the HyPhy package (Pond and Muse, 2005). These were followed by tests to detect different selection scenarios. For each TLR gene, we identified the best-fitting substitution model using the model-selection tool (Delport et al., 2010b) on the Datamonkey webserver (http://www.datamonkey.org, accessed March 2016; Delport et al., 2010a).

The Datamonkey webserver was used to test for evidence of positive, negative, and episodic selection using the single-likelihood ancestor counting (SLAC), the random-effects likelihood (REL; Pond and Frost, 2005), fast unconstrained Bayesian approximation (FUBAR; Murrell et al., 2013), and the mixed-effects model of evolution (MEME; Murrell et al., 2012) methods. Additionally, the branch-site REL (BSR) method 
was used to identify individual lineages under diversifying selection (Pond et al., 2011). The three different codon-based maximum-likelihood methods, SLAC, FUBAR, and REL, estimate $d N / d S$ at every codon in the sequence alignment.

\subsection{Analyses of selective forces on TLR3 and TLR7 in waders}

Data generated by direct sequencing of 18 specimens of $A$. interpres, 22 of $C$. alba and 17 of $C$. ruficollis were used to elucidate the type and level of selection affecting the three species. Sequences were processed, assembled, and aligned using BioEdit, and all polymorphisms were examined by eye. TLR3 and TLR7 haplotypes were reconstructed with PHASE 2.1 (Stephens and Scheet, 2005; Stephens et al., 2001), implemented in DnaSP 5.1 (Librado Sanz et al., 2009), using the default settings: a thinning interval of 1100 burn-in iterations, and 100 main iterations. Genetic diversity indices of TLR3 and TLR7 within and between wader species were calculated using MEGA, as described above.

The haplotypes of the three species were tested for effects of positive selection, using different models implemented in CODEML in the package PAML 4.7 (Yang, 2007). The M1/M2 model tests for positive selection through $d N / d S$ (Wong et al., 2004; Yang et al., 2005). For a conservative detection of sites under ongoing positive selection, the M8a/M8 model was used (Swanson et al., 2003; Wong et al., 2004). Bayes empirical Bayes (BEB; Yang et al., 2005) was used to calculate posterior probabilities of positively selected sites in cases where the likelihood-ratio test was significant. BEB uses maximum-likelihood estimates of parameters and accounts for sampling errors by applying a Bayesian prior. Pairs of models were compared using a likelihood-ratio test.

As a further test of selection at the population level, we used the internal fixed-effects likelihood (IFEL) method on the Datamonkey webserver. IFEL is a codon-based maximum-likelihood method that tests whether sequences sampled from a population have been subjected to selective pressure at the population level (i.e., along the branches internal to each species) (Pond et al., 2006). Sites that were detected to be under positive or negative selection were mapped onto the 3D protein structures that were inferred for TLR3 and TLR7.

\section{Results and discussion}

\subsection{Characterization of TLR3 and TLR7 genes in waders}

Comparison of the TLR3 and TLR7 sequences from the three waders with those from the closely related Killdeer (Charadrius vociferus), human (Homo sapiens), and house mouse (Mus musculus) revealed the amplification of slightly different regions of the two genes in the waders.
The TLR3 primers amplified the central area of the ECD, including several leucine-rich repeat regions (LRR7-LRR18). In contrast, the TLR7 primers amplified the second part of the ECD, covering the last 8 LRRs in the ECD, as well as the LRR C-terminal cap (LRR-CT) transmembrane and Toll Interleukin-1 signalling (TIR) regions (Supplementary material S2, Fig. S1S2).

TLR3 and TLR7 sequences from the three waders had regions with high similarities to those of orthologous mammalian sequences, indicating the presence of structural constraints. We also found polymorphic regions that potentially represent ligand-recognition sites across the two taxonomic groups (Echave et al., 2016) (Supplementary material S2, Fig. S1-S2). Based on TLR3 from mouse and TLR7 from human as templates, the inferred 3D structures of TLR3 and TLR7 in the three waders revealed typical TLR structures: alternating concave and convex descending and ascending lateral surfaces (3CIG, Fig. 1a; 3W3K, Fig. 1b).

\subsection{Diversity in TLR3 and TLR7 genes in waders}

Previous studies have shown that TLR7 might be duplicated in Passeriformes (Cormican et al., 2009), leading to the presence of two or more TLR7 loci and more than two TLR7 AA haplotypes. The results from the present study showed that there were more than two AA haplotypes among the TLR7 clones, confirming that TLR7 is duplicated in $C$. alba and C. ruficollis and appears to be triplicated in A. interpres (although analysing a larger number of clones would be necessary to confirm the exact number of TLR7 copies in the three species) (Supplementary material S3, Table S5). Although we analysed nearly three times as many TLR3 clones (21-28 clones/specimen) as TLR7 clones ( 8 clones/specimen), the sequence alignments consistently showed the presence of two unique AA TLR3 haplotypes in each bird. This suggests that each of the three waders has only one copy of the TLR3 gene.

Consistent with the duplication of TLR7, the sequences of this receptor had greater numbers of segregating sites and higher nucleotide diversity than the TLR3 sequences in all of the three waders. The same results were obtained when analysing sequences obtained by directly sequencing multiple specimens from the three species (Supplementary material S3, Tables S6-S9).

To determine whether the observed AA changes within and across the three wader species have led to alterations in the TLR3 and TLR7 protein structures, we investigated the physicochemical properties and mean chemical distances of AA substitutions in the cloned sequences (Supplementary material S4, Tables S10 and S11, Figs. S3-S6). These analyses revealed that several of the observed AA substitutions indeed caused changes in the side chains' charge, polarity, and the surface electrostatic potential, as well as in the hydropathy indices. The across-

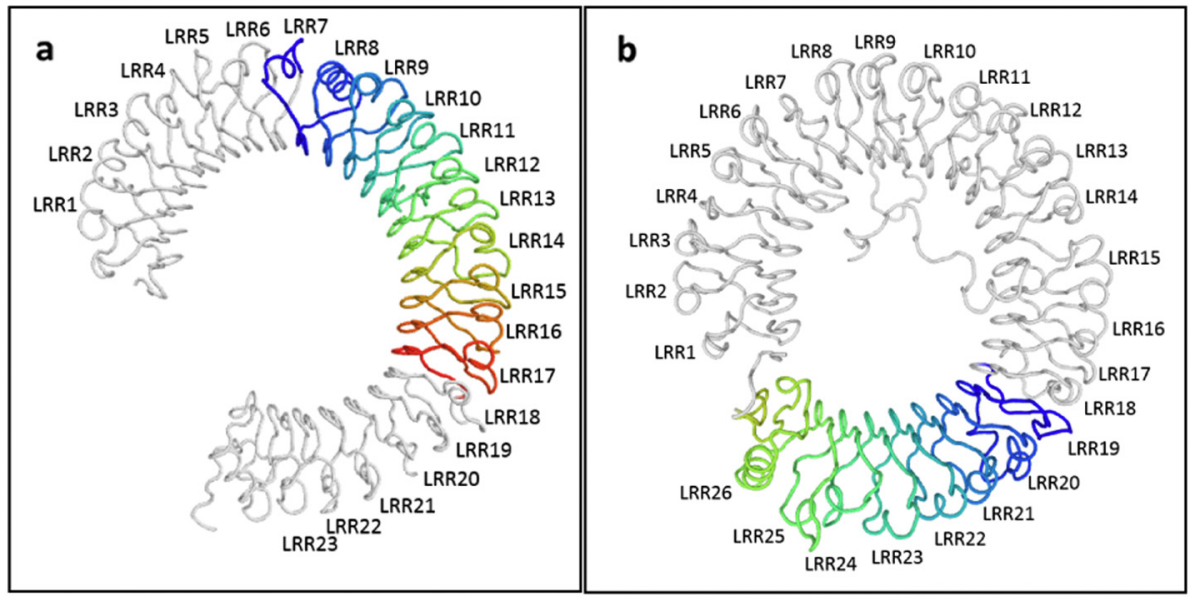

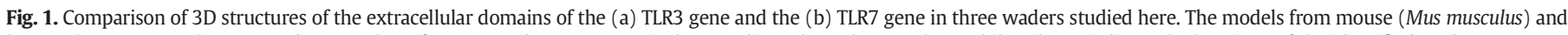

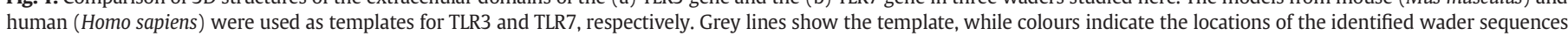
within the structures. (For interpretation of the references to colour in this figure legend, the reader is referred to the web version of this article.) 
species comparison showed that TLR7 sequences had slightly fewer AA polymorphisms than the TLR3 sequences ( 21 vs 26 ) (Fig. 2 illustrates one angle of the physiochemical properties of TLR3 and TLR7 AA substitutions, further information can be found in Figs. S3-S6). These analyses also show high conservancy of TLRs (potentially maintained by negative selection) within the same family. Vinkler et al. (2014) have found higher variation in physiochemical differences, a result that could have originated from comparing TLR structures within class or between taxonomic groups (i.e. birds vs mammals), rather than within a single family.

\subsection{Phylogenetic analysis of TLR3 and TLR7 genes across 50 avian taxa}

The branching pattern of the TLR3 phylogenetic tree was inconsistent with the evolutionary history of the 50 birds inferred from their whole genomes (Jarvis et al., 2014) (Fig. 3). Furthermore, our molecular-clock analysis indicates that the TLR3 sequences of most waders diverged from those of other birds $>60$ million years ago (MYA). The age estimates for major nodes of the TLR3 phylogenetic tree were similar to those reported by Jarvis et al. (2014) and Cracraft et al. (2015), probably because
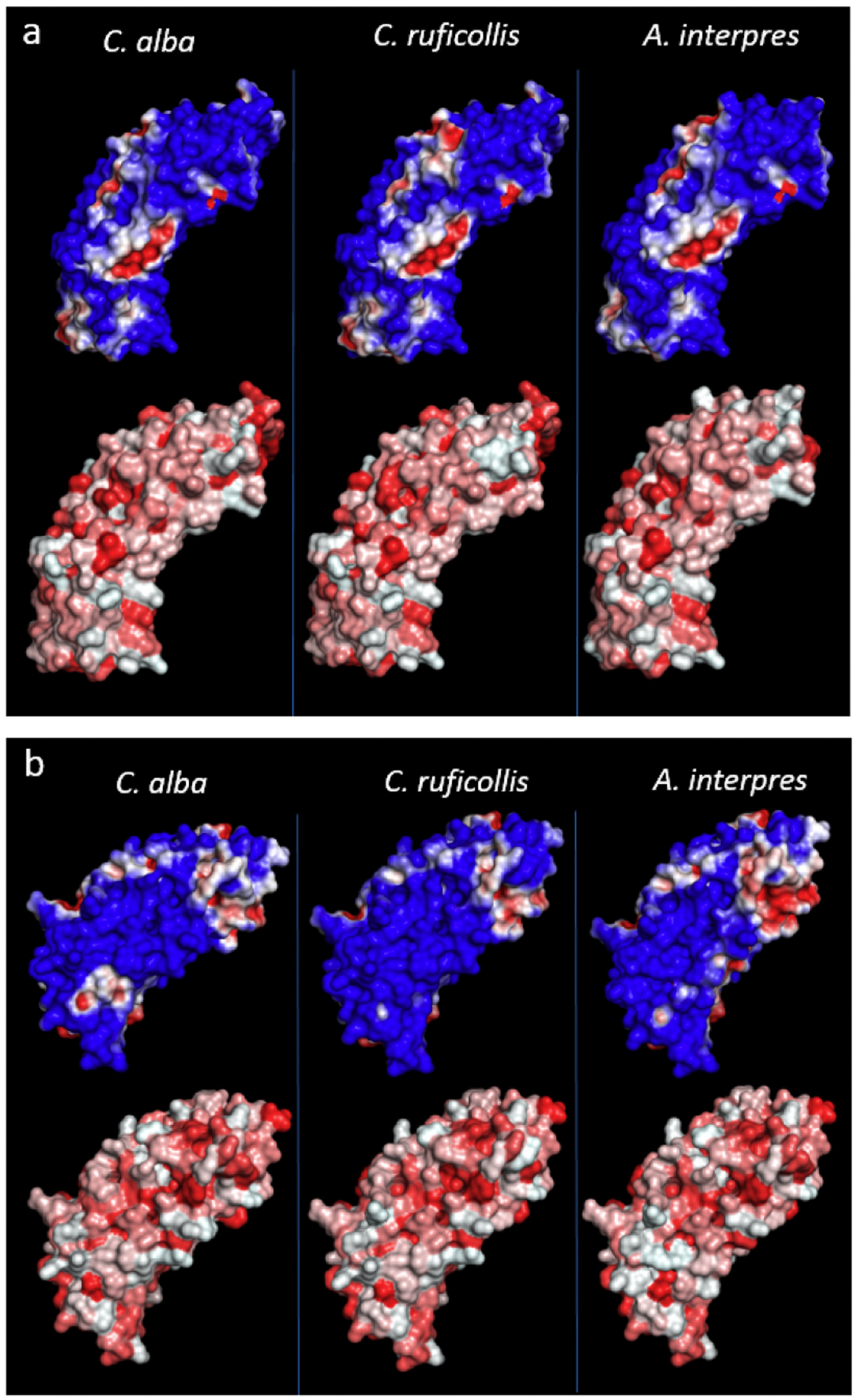

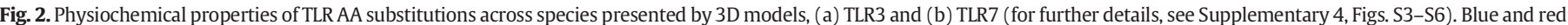

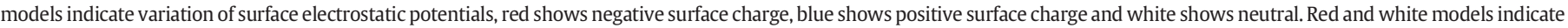

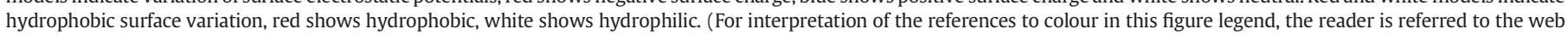
version of this article.) 

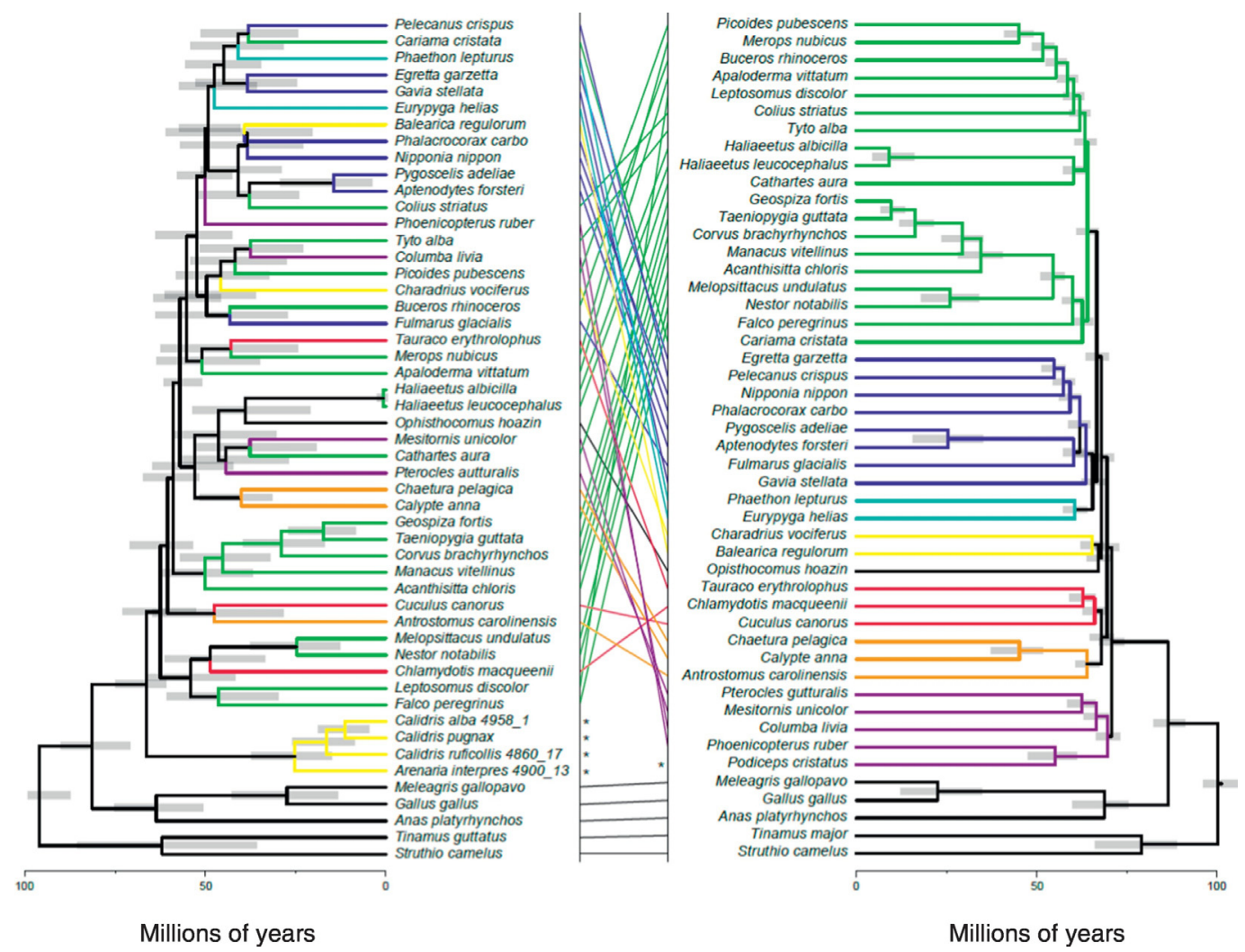

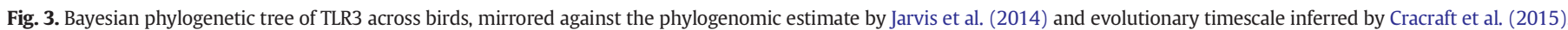

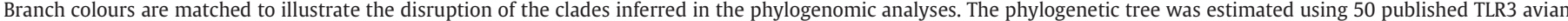

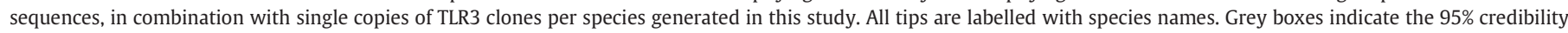

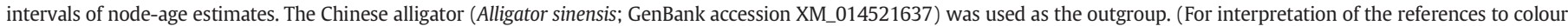
in this figure legend, the reader is referred to the web version of this article.)

a very similar set of calibrations was used for both dating analyses. A notable exception among the waders is that the four migratory waders $(C$. alba, C. ruficollis, A. interpres, and Calidris pugnax) formed a monophyletic group, whereas the only non-migratory wader, Charadrius vociferus, grouped with three very distantly related species: Downy Woodpecker (Picoides pubescens), Rock Dove (Columba livia), and Barn Owl (Tyto $a l b a$ ). This branching pattern suggests that TLR3 is subject to different selection pressures in different wader species.

Charadrius vociferus is a philopatric, occasionally short-distance intracontinental migratory species that only moves within the North American continent under certain conditions (del Hoyo et al., 1992-2013; Sanzenbacher and Haig, 2001). The other four wader species, including Calidris pugnax, are long-distance migrants that use similar inland and coastal stopover sites when flying from their high-latitude breeding areas in the north to their tropical or Southern Hemisphere wintering destinations (del Hoyo et al., 1992-2013; Lisovski et al., 2015; Minton et al., 2011). Thus, they should be exposed to a similar range of pathogens. This difference in migration pattern and habitat use between Charadrius vociferus and the other waders is not reflected in the TLR7 phylogenetic analysis, further indicating different pathogen selection pressures between the TLR3 and TLR7 genes (Barton, 2007), as discussed below.

As in the tree inferred from the TLR3 sequences, we found that the relationships among the TLR7 sequences did not match the phylogenomic relationships among the 50 birds (Fig. 4). In contrast with the TLR3 tree, however, all TLR7 sequences from waders grouped with those from the closely related Charadrius vociferus. Our Bayesian phylogenetic analyses clearly show the duplications of TLR7 in the three waders, but also in Charadrius vociferus and Calidris pugnax, and in two other bird orders, Passeriformes (Taeniopygia guttata, Zebra Finch; Corvus brachyrhynchos, American Crow; and Manacus vitellinus, Golden-collared Manakin) and
Cuculiformes (Cuculus canorus, Common Cuckoo). Although TLR7 duplications have previously been described in several passerines (Cormican et al., 2009; Grueber et al., 2012), our study is the first to describe a third paralogue of TLR7 in the Medium Ground-finch (Geospiza fortis), as well as TLR7 duplications in additional bird species in Charadriiformes and Cuculiformes. Although a genome sequence is available for an additional passerine, the White-crowned Sparrow (Zonotrichia leucophrys), the poor assembly and annotation of the genome meant that it was not possible to confirm whether TLR7 is duplicated in this species. Improved annotations across all bird genomes could lead to the discovery of further TLR7 duplications in other species (Salzberg and Yorke, 2005).

\subsection{Evolution of avian TLR7 and TLR3}

The phylogenetic tree of avian TLR7 revealed that duplicate copies of TLR7 clustered according to the phylogenetic relationships of the species. The TLR7 sequences from both Passeriiformes and Charadriiformes formed individual clades. Importantly, the TLR7 paralogues were more similar within than between species, suggesting recent duplication events.

Multiple duplications across species are known to occur (Pohl et al., 2009), but independent duplications usually display a random pattern across the phylogenetic tree (Bainová et al., 2014). The pattern of duplications across the three avian orders appears to be random, but the duplication pattern within the orders is not. Although this does not make recent, independent duplications impossible, it does make them extremely unlikely. It is possible that Charadriiforms experienced similar selection pressures over the last 10 million years or so, causing this grouping of independent duplications. This does not, however, explain why both the Passeriformes and Cuculiformes show a similar pattern of duplications that occurred around the same time. It is unlikely that 

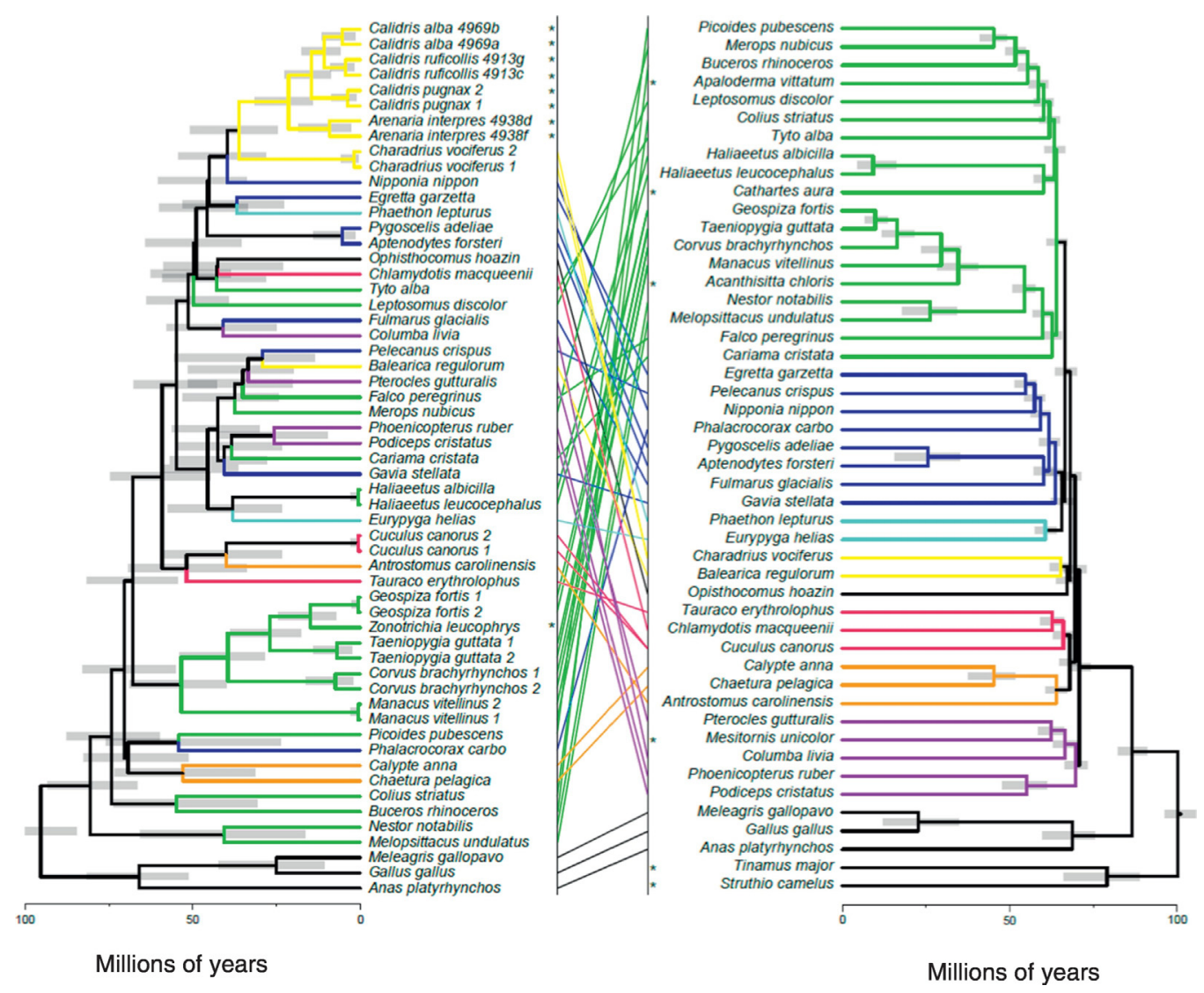

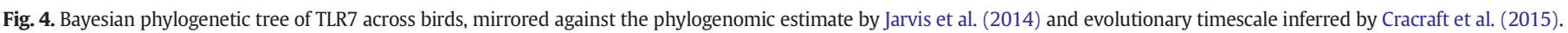

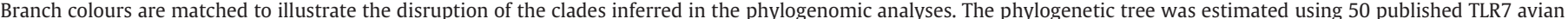

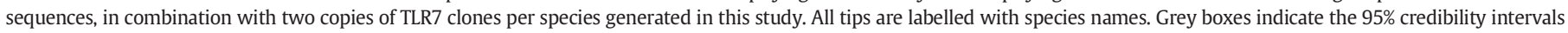

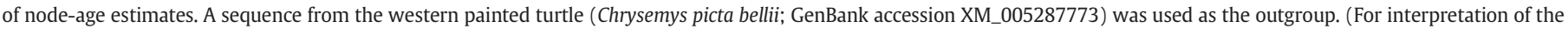
references to colour in this figure legend, the reader is referred to the web version of this article.)

all three orders experienced the same selection pressures, given the diversity of habitats used and the different lifestyles displayed by these birds. Thus, the most likely explanation is that these duplications occurred ancestrally within each order.

An ancestral duplication event, even within an order, should still show a divergent pattern between the copies of the gene. This would produce a phylogenetic pattern in which the paralogues cluster by gene copies rather than by species (Schirrmeister et al., 2012). The observed clustering by species indicates homogenization of the genes, which is a signature of concerted evolution. Concerted evolution maintains the similarity between the two genes, using a combination of crossing-over events and homogenization, with each gene being used as a template (Hurles, 2004; Nei and Hughes, 1992). This process is not unique to avian TLR7, but has also been found to drive the genetic variation of the duplicated TLR1 and TLR2 genes across avian taxa (Alcaide and Edwards, 2011).

Gene duplication has been suggested to lead to an increased amount of gene product, although it does not necessarily double the dosage (Hurles, 2004; Stark and Wahl, 1984). Therefore, extra copies of TLR7 might allow a faster and a more specific response to viral infections in migratory waders. This might provide a selective advantage in the pathogen-host arms race, not only for long-distance migrants but for all birds.

TLR3 duplicates have been discovered in some vertebrates, such as fish (Kongchum et al., 2010), but no paralogues of TLR3 were found in the 50 avian genomes and the three waders studied here. Our results are consistent with the TLR3 gene being highly conserved across vertebrates, with most having only a single copy of the gene recognizing double-stranded RNA (Akira and Takeda, 2004).

\subsection{Signatures of selection in TLR3 and TLR7 across birds}

Comparison of rates of synonymous substitution $(d S)$ and non-synonymous substitution $(d N)$ were similar to those previously calculated in avian TLR3 and TLR7 (Alcaide and Edwards, 2011; Grueber et al., 2014; Mikami et al., 2012), and confirmed the predominance of purifying selection in both genes in all 50 birds ( $d N / d S<1$ for all loci; Table 2$)$. Despite this evidence of purifying selection at the whole-gene level, we detected signals of positive selection at a small number of sites (TLR3 3.2\%; TLR7 2.5\%; Table 2). Nearly twice as many sites were found to be under episodic diversifying selection in TLR3 (9.2\%) compared with TLR7 (5.4\%). In contrast, close to $50 \%$ more sites were under negative selection

Table 2

Selection and diversity statistics for avian TLR3 and TLR7 genes.

\begin{tabular}{|c|c|c|c|c|c|c|c|c|}
\hline \multirow[t]{2}{*}{ Gene } & \multirow{2}{*}{$\begin{array}{l}\text { No. of } \\
\text { Seq. }\end{array}$} & \multirow{2}{*}{$\begin{array}{l}\text { No. of } \\
\text { codons }\end{array}$} & \multirow{2}{*}{$\begin{array}{l}\text { Mean } \\
d N / d S\end{array}$} & \multicolumn{5}{|c|}{ Sites under selection } \\
\hline & & & & BSR & FUBAR & SLAC & REL & MEME \\
\hline \multirow[t]{2}{*}{ TLR3 } & 50 & 260 & 0.38 & 1EDS** & 6PS* & $6 P S^{*}$ & 13PS* & 24EDS* \\
\hline & & & & & 123NS* & 77NS* & $31 N S^{*}$ & \\
\hline \multirow[t]{2}{*}{ TLR7 } & 53 & 297 & 0.34 & OEDS & 5PS* & 5PS* & 12PS* & 16EDS* \\
\hline & & & & & 175NS* & 111NS* & 97NS* & \\
\hline
\end{tabular}

Note - Selection and diversity statistics were calculated using novel sequences from migratory waders and those obtained from published genomes. Mean $d N / d S$ refers to the mean ratio of non-synonymous to synonymous substitution rates. Numbers of sites under episodic diversifying selection (EDS), positive selection (PS), and negative selection (NS) are given for four methods: branch-site REL (BSR), fast unconstrained bayesian approximation (FUBAR); single-likelihood ancestor counting (SLAC), random-effects likelihood (REL), and mixed-effects model of evolution (MEME). ${ }^{*} \mathrm{p} \leq 0.1,{ }^{* *}$ Node35, $\mathrm{p} \leq 0.05$. 
in TLR7 (43.0\%) than in TLR3 (29.6\%). Many of the sites under selection (54\% of the TLR3 and $66 \%$ of TLR7) detected by different models were identified by two or more of the methods used (Supplementary material S5, Tables S12 and S13).

The branch-site model (BSR) found evidence of diversifying selection along a single branch of the TLR3 tree. These results further support that the evolution of the two genes is most likely driven by responses to different types and levels of pathogen exposure. A potential additional explanation for the difference in selection between the two genes, and specifically the larger number of codons under negative selection in the TLR7 ECD, lies in the involvement of this gene in self-recognition. TLR7 recognizes the smallest molecules of any of the TLRs (Tanji et al., 2013) and can recognize self RNA from sick and dying cells signalling apoptosis (Krieg, 2007). Therefore, excessive variation in the TLR7 ECD could potentially cause autoimmune diseases, and would thus be selected against (Richez et al., 2011).

Although the ECD regions are the primary sites of adaptive responses to pathogens, and hence are expected to show high variation, PAMP binding actually requires a rigid structural framework (Bryant et al., 2015). Therefore, the pervasive force of purifying selection on TLR ECDs maintains the conserved structure of these domains to facilitate efficient PAMP recognition and binding (Echave et al., 2016). Despite the presence of strong purifying selection, the mean ratio of nonsynonymous to synonymous substitution rates $(d N / d S=0.36)$ in these two genes is still higher than that found in most other genes (Ellegren, 2008; Zhang and Li, 2004).

We found that 9 of 15 sites (60\%) under selection in TLR3 were identical in the bird genomes to those found in other animals, including other birds and mammals (Alcaide and Edwards, 2011; Areal et al., 2011; Escalera-Zamudio et al., 2015; Grueber et al., 2014; Wlasiuk and Nachman, 2010). Only one of these sites (265) from the waders matched those identified to be under positive selection in other animals (Supplementary material S5, Table S14). Similarly, all but one of the TLR7 sites were under positive selection uniquely in waders compared with other birds and mammals (Alcaide and Edwards, 2011; Areal et al., 2011; Escalera-Zamudio et al., 2015; Fornůsková et al., 2013; Grueber et al., 2014; Jiang et al., 2016; Wlasiuk and Nachman, 2010). Four of the 12 sites (33\%) identified in the bird genomes matched those found in other studies of mammals and birds (Supplementary material S5, Table
S15). These results further indicate that wader TLRs are under different pathogen selection pressure compared with other animals.

Across the three wader species, we found evidence of higher selection pressure in TLR7 than in TLR3 when analysing the populationlevel data (data originating from direct sequencing of several specimens/species; Supplementary material S6, Table S16). Moreover, across the three species, six sites were found to be under positive selection and three sites were found to be affected by negative selection in TLR3. Sequences from $C$. alba had the largest number of positively and negatively selected sites ( $0.88 \%$ of nucleotides analysed). There was no evidence of selection in C. ruficollis (likelihood-ratio test, $\mathrm{p}=0.13$ ), so we could not conduct a Bayes empirical Bayes test. Only $0.25 \%$ of sites were under selection in the sequences from A. intrepres. Within TLR3, half of the positively selected sites were in LRR14, whereas the negatively selected sites were located in LRR9 and LRR10. TLR7 showed 14 and 22 sites under positive and negative selection, respectively, across the three species. Similar to the results from our analysis of TLR3, the largest number of sites under selection was detected in C. alba (1.8\%), followed by $A$. interpres ( $1 \%$ ) and C. ruficollis $(0.8 \%)$. It is important to note that the observed differences between TLR3 and TLR7 may have originated from different regions being analysed in the two TLRs.

The 3D structural modelling of TLR3 revealed a localized patch of purifying selection corresponding to LRR9 and LRR10, indicating that this region is important for maintaining protein structure (Figs. 1 and 5). Positively selected sites are somewhat scattered in LRR9, LRR12, LRR17, with three sites in LRR14. In TLR7, the negatively and positively selected sites were spread throughout the last part of the ECD. Calidris alba had the largest number of sites under selection in both TLR3 and TLR7 across the three species. These results suggest an association between the lack of AIV infection and the observed TLR variations in the species. Further analyses, such as direct correlation of individual TLR3 and TLR7 polymorphism to AIV prevalence, are needed to identify the specific nucleotide variations associated with AIV infection.

\section{Conclusions}

Studies of pathogen dynamics and the underlying evolutionary mechanisms are urgently needed to predict future disease risks for
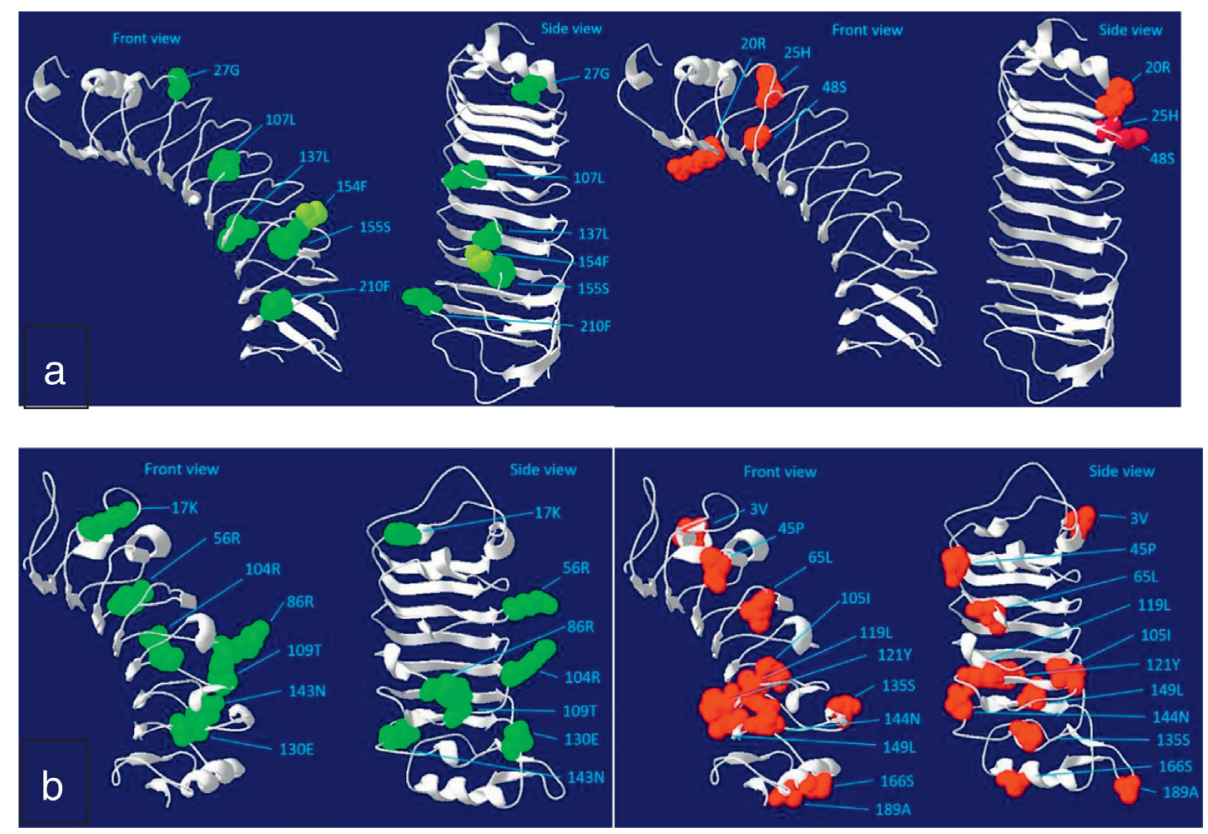

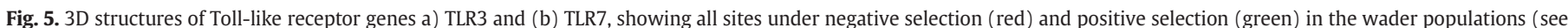

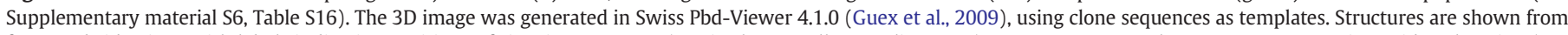

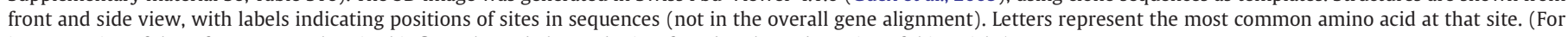
interpretation of the references to colour in this figure legend, the reader is referred to the web version of this article.) 
wildlife and humans alike. By describing the major forms of selection shaping the evolution of avian RNA-sensing Toll-like receptors, our study has laid the groundwork for future investigations of the evolutionary mechanisms underlying infection dynamics and epidemiology. Furthermore, our study is the first to examine innate immune gene polymorphism in long-distance migratory waders in the context of viral infections. AIV infections are prevalent in both $A$. interpres and $C$. ruficollis but have rarely been recorded in C. alba. Our results point towards a possible association between TLR3 polymorphism in C. alba and the lack of AIV in this species. This finding contributes to the identification of candidate loci for future avian eco-immunogenetics research, opening the way for further insights into the impact of immune gene polymorphism on the evolutionary ecology of infectious diseases.

\section{Acknowledgements}

We are grateful to the Victorian Wader Study Group for assistance in collecting the samples. We thank Bethany Hoye, Alice Risely, Meijuan Zhao, and Adam Miller for valuable discussions throughout the project and two anonymous reviewers for their valuable comments.

\section{Appendix A. Supplementary data}

Supplementary data to this article can be found online at http://dx. doi.org/10.1016/j.meegid.2017.05.012.

\section{References}

Aderem, A., Ulevitch, R.J., 2000. Toll-like receptors in the induction of the innate immune response. Nature 406, 782-787.

Akira, S., Takeda, K., 2004. Toll-like receptor signalling. Nat. Rev. Immunol. 4, 499-511.

Alcaide, M., Edwards, S.V., 2011. Molecular evolution of the toll-like receptor multigene family in birds. Mol. Biol. Evol. 28, 1703-1715.

Alexopoulou, L., Holt, A.C., Medzhitov, R., Flavell, R.A., 2001. Recognition of double-stranded RNA and activation of NF-kB by toll-like receptor 3. Nature 413, 732-738.

Altizer, S., Bartel, R., Han, B.A., 2011. Animal migration and infectious disease risk. Science 331, 296-302.

Areal, H., Abrantes, J., Esteves, P.J., 2011. Signatures of positive selection in toll-like receptor (TLR) genes in mammals. BMC Evol. Biol. 11, 368

Asghar, M., Hasselquist, D., Bensch, S., 2011. Are chronic avian haemosporidian infections costly in wild birds? J. Avian Biol. 42, 530-537.

Bainová, H., Králová, T., Bryjová, A., Albrecht, T., Bryja, J., Vinkler, M., 2014. First evidence of independent pseudogenization of toll-like receptor 5 in passerine birds. Dev. Comp. Immunol. 45, 151-155.

Baker, N.A., Sept, D., Joseph, S., Holst, M.J., McCammon, J.A., 2001. Electrostatics of nanosystems: application to microtubules and the ribosome. Proc. Natl. Acad. Sci. 98 10037-10041

Barton, G.M., 2007. Viral recognition by Toll-like receptors. Semin. Immunol. 19 (1): 33-40. http://dx.doi.org/10.1016/j.smim.2007.01.003 ISSN 1044-5323.

Bell, J.K., Mullen, G.E.D., Leifer, C.A., Mazzoni, A., Davies, D.R., Segal, D.M., 2003. Leucinerich repeats and pathogen recognition in toll-like receptors. Trends Immunol. 24, 528-533.

Bell, J.K., Botos, I., Hall, P.R., Askins, J., Shiloach, J., Segal, D.M., Davies, D.R., 2005. The molecular structure of the toll-like receptor 3 ligand-binding domain. Proc. Natl. Acad. Sci. U. S. A. 102, 10976-10980.

Berman, H.M., Westbrook, J., Feng, Z., Gilliland, G., Bhat, T.N., Weissig, H., Shindyalov, I.N. Bourne, P.E., 2000. The protein data Bank. Nucleic Acids Res. 28, 235-242.

Beutler, B., Rehli, M., 2002. Evolution of the TIR, Tolls and TLRs: Functional Inferences from Computational Biology, Toll-like Receptor Family Members and Their Ligands. Springer, pp. 1-21.

Biasini, M., Bienert, S., Waterhouse, A., Arnold, K., Studer, G., Schmidt, T., Kiefer, F., Cassarino, T.G., Bertoni, M., Bordoli, L., 2014. SWISS-MODEL: modelling protein tertiary and quaternary structure using evolutionary information. Nucleic Acids Res. 42, W252-W258.

Botos, I., Segal, D.M., Davies, D.R., 2011. The structural biology of toll-like receptors. Structure 19, 447-459.

Bradley, C.A., Altizer, S., 2005. Parasites hinder monarch butterfly flight: implications for disease spread in migratory hosts. Ecol. Lett. 8, 290-300.

Brownlie, R., Allan, B., 2011. Avian toll-like receptors. Cell Tissue Res.

Bryant, C.E., Gay, N.J., Heymans, S., Sacre, S., Schaefer, L., Midwood, K.S., 2015. Advances in toll-like receptor biology: modes of activation by diverse stimuli. Crit. Rev. Biochem. Mol. Biol. 50, 359-379.

Buehler, D.M., Verkuil, Y.I., Tavares, E.S., Baker, A.J., 2013. Characterization of MHC class I in a long-distance migrant shorebird suggests multiple transcribed genes and intergenic recombination. Immunogenetics $65,211-225$.
Cormican, P., Lloyd, A.T., Downing, T., Connell, S.J., Bradley, D., O'Farrelly, C., 2009. The avian toll-like receptor pathway-subtle differences amidst general conformity. Dev. Comp. Immunol. 33, 967-973.

Cracraft, J., Houde, P., Ho, S.Y., Mindell, D.P., Fjeldså, J., Lindow, B., Edwards, S.V., Rahbek, C., Mirarab, S., Warnow, T., 2015. Response to comment on "whole-genome analyses resolve early branches in the tree of life of modern birds". Science 349, 1460.

Curran, J.M., Ellis, T.M., Robertson, I.D., 2014. Surveillance of Charadriiformes in northern Australia shows species variations in exposure to avian influenza virus and suggests negligible virus prevalence. Avian Dis. 58, 199-204.

De Nardo, D., 2015. Toll-like receptors: activation, signalling and transcriptional modulation. Cytokine 74, 181-189.

DeLano, W.L., 2002. The PyMOL Molecular Graphics System, 1.7.4 ed. DeLano Scientific, San Carlos, CA, USA

Delport, W., Poon, A.F., Frost, S.D., Pond, S.L.K., 2010a. Datamonkey 2010: a suite of phylogenetic analysis tools for evolutionary biology. Bioinformatics 26, 2455-2457.

Delport, W., Scheffler, K., Botha, G., Gravenor, M.B., Muse, S.V., Pond, S.L.K., 2010b. CodonTest: modeling amino acid substitution preferences in coding sequences. PLoS Comput. Biol. 6, e1000885.

Diebold, S.S., Kaisho, T., Hemmi, H., Akira, S., Reis e Sousa, C., 2004. Innate antiviral responses by means of TLR7-mediated recognition of single-stranded RNA. Science 303, 1529-1531.

Dolinsky, T.J., Nielsen, J.E., McCammon, J.A., Baker, N.A., 2004. PDB2PQR: an automated pipeline for the setup of Poisson-Boltzmann electrostatics calculations. Nucleic Acids Res. 32, W665-W667.

Dolinsky, T.J., Czodrowski, P., Li, H., Nielsen, J.E., Jensen, J.H., Klebe, G., Baker, N.A., 2007. PDB2POR: expanding and upgrading automated preparation of biomolecular structures for molecular simulations. Nucleic Acids Res. 35, W522-W525.

Downing, T., L., A.T., O'Farrelly, C., B., D.G., 2010. The differential evolutionary dynamics of avian cytokine and TLR gene classes. J. Immunol. 184, 6993-7000.

Drummond, A.J., Ho, S.Y., Phillips, M.J., Rambaut, A., 2006. Relaxed phylogenetics and dating with confidence. PLoS Biol. 4, e88.

Drummond, A.J., Suchard, M.A., Xie, D., Rambaut, A., 2012. Bayesian phylogenetics with BEAUti and the BEAST 1.7. Mol. Biol. Evol. 29, 1969-1973.

Echave, J., Spielman, S.J., Wilke, C.O., 2016. Causes of evolutionary rate variation among protein sites. Nat. Rev. Genet. 17, 109-121.

Ekblom, R., Saether, S.A., Jacobsson, P., Fiske, P., Sahlman, T., Grahn, M., Kålås, J.A., Höglund, J., 2007. Spatial pattern of MHC class II variation in the great snipe (Gallinago media). Mol. Ecol. 16, 1439-1451.

Ekblom, R., Sæther, S.A., Fiske, P., Kålås, J.A., Höglund, J., 2010. Balancing selection, sexual selection and geographic structure in MHC genes of great snipe. Genetica 138, 453-461.

Ellegren, H., 2008. Comparative genomics and the study of evolution by natural selection. Mol. Ecol. 17, 4586-4596.

Escalera-Zamudio, M., Zepeda-Mendoza, M.L., Loza-Rubio, E., Rojas-Anaya, E., MéndezOjeda, M.L., Arias, C.F., Greenwood, A.D., 2015. The evolution of bat nucleic acid-sensing toll-like receptors. Mol. Ecol. 24, 5899-5909.

Ferenczi, M., 2016. Avian Influenza Virus Dynamics in Australian Wild Birds. School of Life and Envrionmental Sciences. Deakin University, Waurn Ponds, Vic, Australia, p. 179.

Figuerola, J., Green, A.J., 2000. Haematozoan parasites and migratory behaviour in waterfowl. Evol. Ecol. 14, 143-153.

Fornůsková, A., Vinkler, M., Pagès, M., Galan, M., Jousselin, E., Cerqueira, F., Morand, S., Charbonnel, N., Bryja, J., Cosson, J.-F., 2013. Contrasted evolutionary histories of two toll-like receptors (TLR4 and TLR7) in wild rodents (MURINAE). BMC Evol. Biol. 13, 194.

Fritzsche McKay, A., Hoye, B.J., 2016. Are migratory animals superspreaders of infection? Integr. Comp. Biol. 56, 260-267.

Gay, N.J., Gangloff, M., 2007. Structure and function of toll receptors and their ligands. Annu. Rev. Biochem. 76, 141-165.

van Gils, J.A., Munster, V.J., Radersma, R., Liefhebber, D., Fouchier, R.A., Klaassen, M., 2007. Hampered foraging and migratory performance in swans infected with low-pathogenic avian influenza a virus. PLoS One 2, e184.

Gonzalez-Quevedo, C., Spurgin, L.G., Illera, J.C., Richardson, D.S., 2015. Drift, not selection, shapes toll-like receptor variation among oceanic island populations. Mol. Ecol. 24, 5852-5863.

Grantham, R., 1974. Amino acid difference formula to help explain protein evolution. Science $185,862-864$.

Grueber, C.E., Wallis, G.P., King, T.M., Jamieson, I.G., 2012. Variation at innate immunity toll-like receptor genes in a bottlenecked population of a new zealand robin. PLoS One 7, e45011.

Grueber, C.E., Wallis, G.P., Jamieson, I.G., 2014. Episodic positive selection in the evolution of avian toll-like receptor innate immunity genes. PLoS One 9, e89632.

Grueber, C.E., Knafler, G.J., King, T.M., Senior, A.M., Grosser, S., Robertson, B., Weston, K.A., Brekke, P., Harris, C.L.W., Jamieson, I.G., 2015. Toll-like receptor diversity in 10 threatened bird species: relationship with microsatellite heterozygosity. Conserv. Genet. 16.

Guex, N., Peitsch, M.C., Schwede, T., 2009. Automated comparative protein structure modeling with SWISS-MODEL and Swiss-PdbViewer: a historical perspective. Electrophoresis 30, S162-S173.

Hall, T.A., 1999. BioEdit: a user-friendly biological sequence alignment editor and analysis program for windows 95/98/NT. Nucleic Acids Symp. Ser. 41, 95-98.

Hellgren, O., 2015. Allelic variation at innate immune genes (avian $\beta$-defensins), within a natural population of great tits. J. Avian Biol. 46, 113-118.

del Hoyo, J., Elliott, A., Sargatal, J., Cabot, J., 1992-2013. Handbook of the Birds of the World. Lynx Edicions, Barcelona.

Hu, X., Zou, H., Qin, A., Qian, K., Shao, H., Ye, J., 2015. Activation of toll-like receptor 3 inhibits Marek's disease virus infection in chicken embryo fibroblast cells. Arch. Virol. $1-8$.

Hurles, M., 2004. Gene duplication: the genomic trade in spare parts. PLoS Biol. 2. 900-904. 
Jarvis, E.D., Mirarab, S., Aberer, A.J., Li, B., Houde, P., Li, C., Ho, S.Y.W., Faircloth, B.C., Nabholz, B., Howard, J.T., Suh, A., Weber, C.C., da Fonseca, R.R., Li, J., Zhang, F., Li, H., Zhou, L., Narula, N., Liu, L., Ganapathy, G., Boussau, B., Bayzid, M.S., Zavidovych, V., Subramanian, S., Gabaldón, T., Capella-Gutiérrez, S., Huerta-Cepas, J., Rekepalli, B., Munch, K., Schierup, M., Lindow, B., Warren, W.C., Ray, D., Green, R.E., Bruford, M.W., Zhan, X., Dixon, A., Li, S., Li, N., Huang, Y., Derryberry, E.P., Bertelsen, M.F., Sheldon, F.H., Brumfield, R.T., Mello, C.V., Lovell, P.V., Wirthlin, M., Schneider, M.P.C., Prosdocimi, F., Samaniego, J.A., Velazquez, A.M.V., Alfaro-Núñez, A., Campos, P.F., Petersen, B., Sicheritz-Ponten, T., Pas, A., Bailey, T., Scofield, P., Bunce, M., Lambert, D.M., Zhou, Q., Perelman, P., Driskell, A.C., Shapiro, B., Xiong, Z., Zeng, Y., Liu, S., Li, Z., Liu, B., Wu, K., Xiao, J., Yinqi, X., Zheng, Q., Zhang, Y., Yang, H., Wang, J., Smeds, L. Rheindt, F.E., Braun, M., Fjeldsa, J., Orlando, L., Barker, F.K., Jønsson, K.A., Johnson, W., Koepfli, K.-P., O'Brien, S., Haussler, D., Ryder, O.A., Rahbek, C., Willerslev, E., Graves, G.R., Glenn, T.C., McCormack, J., Burt, D., Ellegren, H., Alström, P., Edwards, S.V., Stamatakis, A., Mindell, D.P., Cracraft, J., Braun, E.L., Warnow, T., Jun, W., Gilbert, M.T.P., Zhang, G., 2014. Whole-genome analyses resolve early branches in the tree of life of modern birds. Science 346, 1320-1331.

Jarvis, E.D., Mirarab, S., Aberer, A.J., Li, B., Houde, P., Li, C., Ho, S.Y.W., Faircloth, B.C., Nabholz, B., Howard, J.T., Suh, A., Weber, C.C., da Fonseca, R.R., Alfaro-Núñez, A., Narula, N., Liu, L. Burt, D., Ellegren, H., Edwards, S.V., Stamatakis, A., Mindell, D.P., Cracraft, J., Braun, E.L., Warnow, T., Jun, W., Gilbert, M.T.P., Zhang, G., 2015. Phylogenomic analyses data of the avian phylogenomics project. GigaScience 4, 1-9.

Jiang, H., Li, J., Li, L., Zhang, X., Yuan, L., Chen, J., 2016. Selective evolution of toll-like receptors 3, 7, 8, and 9 in bats. Immunogenetics 1-15.

Klaassen, M., Hoye, B.J., Nolet, B.A., Buttemer, W.A., 2012. Ecophysiology of avian migration in the face of current global hazards. Philos. Trans. R. Soc. Lond. B 367, 1719-1732.

Kongchum, P., Palti, Y., Hallerman, E.M., Hulata, G., David, L., 2010. SNP discovery and development of genetic markers for mapping innate immune response genes in common carp (Cyprinus carpio). Fish Shellfish Immunol. 29, 356-361.

Koprivnikar, J., Leung, T.L., 2015. Flying with diverse passengers: greater richness of parasitic nematodes in migratory birds. Oikos 124, 399-405.

Krauss, S., Stallknecht, D.E., Negovetich, N.J., Niles, L.J., Webby, R.J., Webster, R.G., 2010. Coincident ruddy turnstone migration and horseshoe crab spawning creates an ecological 'hot spot' for influenza viruses. Proc. R. Soc. B Biol. Sci. 277, 3373-3379.

Krieg, A.M., 2007. The toll of too much TLR7. Immunity 27, 695-697.

Leroy, E.M., Epelboin, A., Mondonge, V., Pourrut, X., Gonzalez, J.-P., Muyembe-Tamfum, J.J., Formenty, P., 2009. Human ebola outbreak resulting from direct exposure to fruit bats in Luebo, Democratic Republic of Congo, 2007. Vector Borne Zoonotic Dis. 9, 723-728.

Li, Y., Xu, Q., Zhang, T., Gao, M., Wang, Q., Han, Z., Shao, Y., Ma, D., Liu, S., 2015. Host avian beta-defensin and toll-like receptor responses of pigeons following infection with pigeon paramyxovirus type 1. Appl. Environ. Microbiol. 81, 6415-6424.

Librado Sanz, P., Rozas, L., Julio, A., 2009. DnaSP v5: a software for comprehensive analysis of DNA polymorphism data. Bioinformatics 25 (11), 1451-1452.

Lisovski, S., Gosbell, K., Christie, M., Hoye, B., Klaassen, M., Stewart, I., Taysom, A., Minton, C., 2015. Movement patterns of Sanderling (Calidris alba) along the East Asian Australasian Flyway and a comparison of methods to identify crucial areas for conservation. Emu 116 (2), 168-177.

Liu, L., Botos, I., Wang, Y., Leonard, J.N., Shiloach, J., Segal, D.M., Davies, D.R., 2008. Structural basis of toll-like receptor 3 signaling with double-stranded RNA. Science 320, 379-381.

MacDonald, M.R.W., Xia, J., Smith, A.L., Magor, K.E., 2007. The duck toll like receptor 7: genomic organization, expression and function. Mol. Immunol. 45, 2055-2061.

Maniatis, T., Fritsch, E.F., Sambrook, J., 1982. Molecular Cloning: A Laboratory Manual. Cold Spring Harbor Laboratory, Cold Spring Harbor, NY.

Marius, G., Xiangming, X., Joseph, D., Juan, L., Vincent, M., Jan, S., 2006. Anatidae migration in the western Palearctic and spread of highly pathogenic avian influenza H5N1 virus. Emerg. Infect. Dis. 12, 1650

Maxted, A., Sitters, H., Luttrell, P., Dey, A., Kalasz, K., Niles, L., Stallknecht, D.E., 2016. Spring migration stopover ecology of avian influenza virus shorebird hosts at Delaware Bay. Avian Dis. 60, 394-405.

Medzhitov, R., Janeway, C.A., 1997. Innate immunity: the virtues of a nonclonal system of recognition. Cell 91, 295-298.

Medzhitov, R., Janeway, J.C., 2000. The toll receptor family and microbial recognition. Trends Microbiol. 8, 452-456.

Mikami, T., Miyashita, H., Takatsuka, S., Kuroki, Y., Matsushima, N., 2012. Molecular evolution of vertebrate toll-like receptors: evolutionary rate difference between their leucine-rich repeats and their TIR domains. Gene 503, 235-243.

Minias, P., Whittingham, L.A., Dunn, P.O., 2016. Coloniality and migration are related to selection on MHC genes in birds. Evolution 71, 432-441.

Minton, C., Gosbell, K., Johns, P., Christie, M., Fox, J.W., Afanasyev, V., 2010. Initial results from light level geolocator trials on Ruddy turnstone Arenaria interpres reveal unexpected migration route. Wader Study Group Bull. 117, 9-14.

Minton, C., Gosbell, K., Johns, P., Fox, J., Afanasyev, V., 2011. Recoveries and flag sightings of waders which spend the non-breeding season in Australia. Stilt 59, 17-43.

Misch, E., Hawn, T., 2008. Toll-like receptor polymorphisms and susceptibility to human disease. Clin. Sci. 114, 347-360.

Møller, A.P., Erritzøe, J., 1998. Host immune defence and migration in birds. Evol. Ecol. 12, 945-953.

Møller, A.P., de Lope, F., Saino, N., 2004. Parasitism, immunity, and arrival date in a migratory bird, the barn swallow. Ecology 85, 206-219.

Murrell, B., Wertheim, J.O., Moola, S., Weighill, T., Scheffler, K., Pond, S.L.K., 2012. Detecting individual sites subject to episodic diversifying selection. PLoS Genet. 8, e1002764.

Murrell, B., Moola, S., Mabona, A., Weighill, T., Sheward, D., Pond, S.L.K., Scheffler, K., 2013. FUBAR: a fast, unconstrained bayesian approximation for inferring selection. Mol. Biol. Evol. 30, 1196-1205.
Nei, M., Hughes, A., 1992. Balanced polymorphism and evolution by the birth-and-death process in the MHC loci. In: Tsuji, K., Aizawa, M., Sasazuki, T. (Eds.), Histocompatibility Workshop and Conference. Oxford university Press, Oxford UK.

Netea, M.G., Wijmenga, C., O'Neill, L.A.J., 2012. Genetic variation in toll-like receptors and disease susceptibility. Nat. Immunol. 13, 535-542.

Owen, J., Moore, F., Panella, N., Edwards, E., Bru, R., Hughes, M., Komar, N., 2006. Migrating birds as dispersal vehicles for West Nile virus. EcoHealth 3, 79-85.

Philbin, V.J., Iqbal, M., Boyd, Y., Goodchild, M.J., Beal, R.K., Bumstead, N., Young, J., Smith A.L., 2005. Identification and characterization of a functional, alternatively spliced toll-like receptor 7 (TLR7) and genomic disruption of TLR8 in chickens. Immunology $114,507-521$.

Pohl, N., Sison-Mangus, M.P., Yee, E.N., Liswi, S.W., Briscoe, A.D., 2009. Impact of duplicate gene copies on phylogenetic analysis and divergence time estimates in butterflies. BMC Evol. Biol. 9, 99.

Pond, S.L.K., Frost, S.D., 2005. Not so different after all: a comparison of methods for detecting amino acid sites under selection. Mol. Biol. Evol. 22, 1208-1222.

Pond, S.L.K., Muse, S.V., 2005. HyPhy: hypothesis testing using phylogenies, statistical methods in molecular evolution. Springer, pp. 125-181.

Pond, S.L.K., Frost, S.D., Grossman, Z., Gravenor, M.B., Richman, D.D., Brown, A.J.L., 2006. Adaptation to different human populations by HIV-1 revealed by codon-based analyses PLoS Comput. Biol. 2, e62.

Pond, S.L.K., Murrell, B., Fourment, M., Frost, S.D., Delport, W., Scheffler, K., 2011. A random effects branch-site model for detecting episodic diversifying selection. Mol. Biol. Evol. 28, 3033-3043.

Råberg, L., Grahn, M., Hasselquist, D., Svensson, E., 1998. On the adaptive significance of stress-induced immunosuppression. Proc. R. Soc. Lond. B Biol. Sci. 265, 1637-1641.

Resa-Infante, P., Jorba, N., Coloma, R., Ortin, J., 2011. The influenza RNA synthesis machine advances in its structure and function. RNA Biol. 8, 207-215.

Richez, C., Blanco, P., Rifkin, I., Moreau, J.-F., Schaeverbeke, T., 2011. Role for toll-like receptors in autoimmune disease: the example of systemic lupus erythematosus. Joint Bone Spine 78, 124-130.

Roach, J.C., Glusman, G., Rowen, L., Kaur, A., Purcell, M.K., Smith, K.D., Hood, L.E., Aderem, A. 2005. The evolution of vertebrate toll-like receptors. Proc. Natl. Acad. Sci. U. S. A. 102 9577-9582.

Romanov, M.N., Dodgson, J.B., Gonser, R.A., Tuttle, E.M., 2011. Comparative BAC-based mapping in the white-throated sparrow, a novel behavioral genomics model, using interspecies overgo hybridization. BMC. Res. Notes 4, 211.

Salzberg, S.L., Yorke, J.A., 2005. Beware of mis-assembled genomes. Bioinformatics 21 4320-4321.

Sanzenbacher, P., Haig, S.M., 2001. Killdeer population trends in North America. J. Field Ornithol. 72, 160-169.

Schirrmeister, B.E., Dalquen, D.A., Anisimova, M., Bagheri, H.C., 2012. Gene copy number variation and its significance in cyanobacterial phylogeny. BMC Microbiol. 12, 1.

Schröder, N.W., Schumann, R.R., 2005. Single nucleotide polymorphisms of toll-like receptors and susceptibility to infectious disease. Lancet Infect. Dis. 5, 156-164.

Schultz, J., Milpetz, F., Bork, P., Ponting, C.P., 1998. SMART, a simple modular architecture research tool: identification of signaling domains. Proc. Natl. Acad. Sci. 95, 5857-5864

Stamatakis, A., 2014. RAxML version 8: a tool for phylogenetic analysis and post-analysis of large phylogenies. Bioinformatics 30, 1312-1313.

Stark, G.R., Wahl, G.M., 1984. Gene amplification. Annu. Rev. Biochem. 53, 447-491.

Stephens, M., Scheet, P., 2005. Accounting for decay of linkage disequilibrium in haplotype inference and missing-data imputation. Am. J. Hum. Genet. 76, 449-462.

Stephens, M., Smith, N.J., Donnelly, P., 2001. A new statistical method for haplotype reconstruction from population data. Am. J. Hum. Genet. 68, 978-989.

Swanson, W.J., Nielsen, R., Yang, Q., 2003. Pervasive adaptive evolution in mammalian fertilization proteins. Mol. Biol. Evol. 20, 18-20.

Tajima, F., Nei, M., 1984. Estimation of evolutionary distance between nucleotide sequences. Mol. Biol. Evol. 1, 269-285.

Takeda, K., Kaisho, T., Akira, S., 2003. Toll-like receptors. Annu. Rev. Immunol. 21, 335-376.

Tamura, K., Stecher, G., Peterson, D., Filipski, A., 2013. MEGA6: molecular evolutionary genetics analysis version 6.0. Mol. Biol. Evol. 30 (12), 2725-2729.

Tanji, H., Ohto, U., Shibata, T., Miyake, K., Shimizu, T., 2013. Structural reorganization of the toll-like receptor 8 dimer induced by agonistic ligands. Science 339, $1426-1429$.

Tschirren, B., Andersson, M., Scherman, K., Westerdahl, H., Mittl, P.R.E., Råberg, L., 2013. Polymorphisms at the innate immune receptor TLR2 are associated with Borrelia infection in a wild rodent population. Proc. R. Soc. Lond. B Biol. Sci. 280, 20130364.

Verhagen, J.H., Herfst, S., Fouchier, R.A.M., 2015. How a virus travels the world. Science $347,616$.

Vinkler, M., Bainová, H., Bryja, J., 2014. Protein evolution of toll-like receptors 4, 5 and 7 within Galloanserae birds. Genet. Sel. Evol. 46:72. http://dx.doi.org/10.1186/s12711014-0072-6.

Wang, T., Town, T., Alexopoulou, L., Anderson, J.F., Fikrig, E., Flavell, R.A., 2004. Toll-like receptor 3 mediates West Nile virus entry into the brain causing lethal encephalitis. Nat. Med. 10, 1366-1373.

Weast, R.C., Lide, D.R., 1928-, 1991. CRC Handbook of Chemistry and Physics. 72nd ed. CRC press, Cleveland, Ohio.

Werling, D., Jann, O.C., Offord, V., Glass, E.J., Coffey, T.J., 2009. Variation matters: TLR structure and species-specific pathogen recognition. Trends Immunol. 30, 124-130.

Wilcove, D.S., Wikelski, M., 2008. Going, going, gone: is animal migration disappearing. PLoS Biol. 6, e188.

Wlasiuk, G., Nachman, M.W., 2010. Adaptation and constraint at toll-like receptors in primates. Mol. Biol. Evol. 27, 2172-2186.

Wong, W.S., Yang, Z., Goldman, N., Nielsen, R., 2004. Accuracy and power of statistical methods for detecting adaptive evolution in protein coding sequences and for identifying positively selected sites. Genetics 168, 1041-1051. 
Yang, Z., 2007. PAML 4: phylogenetic analysis by maximum likelihood. Mol. Biol. Evol. 24, $1586-1591$.

Yang, Z., Wong, W.S., Nielsen, R., 2005. Bayes empirical Bayes inference of amino acid sites under positive selection. Mol. Biol. Evol. 22, 1107-1118.

Zhang, L.Q., Li, W.H., 2004. Mammalian housekeeping genes evolve more slowly than tissue-specific genes. Mol. Biol. Evol. 21, 236-239.

Zhang, G., Li, C., Li, Q., Li, B., Larkin, D.M., Lee, C., Storz, J.F., Antunes, A., Greenwold, M.J. Meredith, R.W., Ödeen, A., Cui, J., Zhou, O., Xu, L., Pan, H., Wang, Z., Jin, L., Zhang, P. Hu, H., Yang, W., Hu, J., Xiao, J., Yang, Z., Liu, Y., Xie, Q., Yu, H., Lian, J., Wen, P., Zhang F., Li, H., Zeng, Y., Xiong, Z., Liu, S., Zhou, L., Huang, Z., An, N., Wang, J., Zheng, Q., Xiong, Y., Wang, G., Wang, B., Wang, J., Fan, Y., da Fonseca, R.R., Alfaro-Núñez, A., Schubert, M., Orlando, L., Mourier, T., Howard, J.T., Ganapathy, G., Pfenning, A Whitney, O., Rivas, M.V., Hara, E., Smith, J., Farré, M., Narayan, J., Slavov, G., Romanov, M.N., Borges, R., Machado, J.P., Khan, I., Springer, M.S., Gatesy, J., Hoffmann, F.G., Opazo, J.C., Håstad, O., Sawyer, R.H., Kim, H., Kim, K.-W., Kim, H.J., Cho, S., Li, N.
Huang, Y., Bruford, M.W., Zhan, X., Dixon, A., Bertelsen, M.F., Derryberry, E., Warren, W., Wilson, R.K., Li, S., Ray, D.A., Green, R.E., O'Brien, S.J., Griffin, D., Johnson, W.E., Haussler, D., Ryder, O.A., Willerslev, E., Graves, G.R., Alström, P., Fjeldså, J., Mindell, D.P., Edwards, S.V., Braun, E.L., Rahbek, C., Burt, D.W., Houde, P., Zhang, Y., Yang, H., Wang, J., Jarvis, E.D., Gilbert, M.T.P., Wang, J., Ye, C., Liang, S., Yan, Z., Zepeda, M.L., Campos, P.F., Velazquez, A.M.V., Samaniego, J.A., Avila-Arcos, M., Martin, M.D., Barnett, R., Ribeiro, A.M., Mello, C.V., Lovell, P.V., Almeida, D., Maldonado, E., Pereira, J., Sunagar, K., Philip, S., Dominguez-Bello, M.G., Bunce, M., Lambert, D., Brumfield, R.T., Sheldon, F.H., Holmes, E.C., Gardner, P.P., Steeves, T.E., Stadler, P.F., Burge, S.W., Lyons, E., Smith, J., McCarthy, F., Pitel, F., Rhoads, D., Froman, D.P., 2014. Comparative genomics reveals insights into avian genome evolution and adaptation. Science 346 , $1311-1320$.

Zhang, M., Song, K., Li, C., Chen, Z., Ding, C., Liu, G., 2015. Molecular cloning of Peking duck toll-like receptor 3 (duTLR3) gene and its responses to reovirus infection. Virol. J. 12, $1-8$. 